\title{
A Utilização do Diagrama V como Estruturador de Atividades Experimentais com videoanálise em Sala de Aula de Física no Ensino Médio
}

\section{The Use of Diagram V as a Structurer of Experimental Activities with Video Analysis in a Physics Classroom in High School}

\author{
A. R. S. TRABACH*1 ${ }^{* 1}$ L. FERraCiOli ${ }^{2}$ \\ ${ }^{1}$ Escola Estadual de Ensino Fundamental e Médio São João Batista. \\ ${ }^{2}$ Universidade Federal do Espírito Santo.
}

\begin{abstract}
Resumo
Este trabalho apresenta e descreve a utilização do Vê epistemológico de Gowin como elemento estruturador e instrumento de coleta de dados em uma atividade experimental em aulas de Física, empregando a técnica da vídeo-análise, através do software Tracker com 22 estudantes da primeira série do ensino médio. É descrita uma atividade na qual os estudantes, após já estarem familiarizados com o Diagrama $V$ e com a vídeo-análise, estudaram o movimento de queda de corpos. Os resultados apontam a potencialidade da ferramenta epistemológica em levar os estudantes a organizarem o procedimento experimental, a buscarem coerência, estabelecendo a reflexão entre teoria e prática e construindo uma síntese e uma conclusão objetivas sobre o tópico abordado. Em relação ao professor, identificou-se a possibilidade do acompanhamento do desenvolvimento conceitual e metodológico dos estudantes durante a atividade experimental.
\end{abstract}

Palavras-chave: Diagrama V. Vídeo-análise. Ensino de Física.

*fisico.trabach@gmail.com 


\begin{abstract}
This work presents and describes the use of Diagram $V$ as a structuring element and instrument of data collection in an experimental activity in physics classes employing the technique of video analysis through the software Tracker with students of the first year of high school. An activity is described in which the students, after already being familiar with Diagram $V$ and with the video-analysis, studied the movement of falling bodies. Results point to the potential of Diagram $V$ to lead the students to organize the experimental procedure, to seek coherence and to promote the reflection between theory and practice, and to build the synthesis and conclusion about the topic addressed. In relation to the teacher, Diagram $V$ made it possible to follow the students during the development of the experimental activity, besides providing data for analysis of students' conceptual and methodological development.
\end{abstract}

Keywords: Diagram V. Video-analysis. Physics Teaching.

\title{
I. INTRODUÇÃO
}

O ensino de ciências, e em especial o ensino de física, empregando a realização de atividades experimentais vem passando por questionamentos e profundas reflexões ao longo das últimas décadas. Borges (2002) nos traz um panorama sobre os diversos aspectos relacionados à realização de atividades experimentais utilizando o laboratório escolar. Silva e Gaspar (2009) nos alertam para a necessidade de que a realização experimental sustentem um processo de significação do mundo, traçando um paralelo como campo da simulação que traça um jogo entre elementos e relações, mantendo correspondência com seus análogos no plano do fenômeno.

Analogamente à simulação, tem-se a relação entre o plano de análise e o fenômeno quando tomamos a vídeo-análise, que, segundo Leitão, Teixeira e Rocha (2011), consiste em fazer uma tomada de vídeo de um fenômeno simples e, na sequencia, executar minucioso exame do fenômeno gravado através de ferramenta de análise de grandezas observáveis e quantificáveis da física desse fenômeno.

É preciso que se adote estratégias de abordagem das atividades experimentais que promovam o engajamento, a aprendizagem e a compreensão dos conceitos, que estimule os estudantes a reflexão e a tomada de consciência acerca da razão da execução dos processos e de sua finalidade. E este é o ponto chave para inserirmos o Diagrama $V$, também conhecido como Vê epistemológico de Gowin. Definido por Gowin (1981) como um instrumento heurístico para ajudar a desvelar o processo de produção de conhecimento, levando o aprendiz a identificar os conceitos, as teorias, os registros e as metodologias, utilizados na produção de um determinado conhecimento. Com isso, pode-se estabelecer um elo importante entre o Diagrama V e pressupostos necessários à aprendizagem significativa, interação não-arbitrária e não-literal com conhecimentos prévios especificamente relevantes, os chamados subsunçores. 
Neste contexto, este estudo foi desenvolvido visando investigar a utilização do Diagrama $\mathrm{V}$ como elemento estruturador e orientador de uma atividade experimental na perspectiva básica de articular o pensar e o fazer sobre a atividade experimental na busca de coerência, organização e orientação dos trabalhos durante a prática experimental seja no contexto do laboratório ou de sala de aula, sendo este último o foco deste artigo.

\section{ReFERENCIAL TEÓRICO}

A seguir são apresentadas as ideais básicas do Diagrama V, alguns resultados de sua utilização no contexto do ensino de Física e a estruturação utilizada nesse estudo.

\section{II.1. O Vê Epistemológico de Gowin ou Diagrama V}

O Vê epistemológico de Gowin, ou simplesmente Diagrama V, é um instrumento que foi proposto com o intuito de auxiliar na compreensão de como se dá a construção do conhecimento, bem como uma ferramenta de "desempacotamento" do conhecimento condensado em artigos, livros e outras formas de divulgação em diversas áreas (FERRACIOLI, 2005; 2018).

A procura por uma forma de expressar como é dada a construção do conhecimento que pudesse ser descrita, reproduzida e aplicada no estudo de fenômenos de maneira geral levou Gowin (1981) a iniciar pelo estabelecimento de cinco questões que, devidamente respondidas, refletiriam a compreensão de como se dá a contínua construção de novos conceitos e significados, numa perspectiva de aprendizagem significativa das novas informações apresentadas. São estas as questões:

1. Qual a questão básica do estudo?

2. Quais os conceitos-chave envolvidos no estudo?

3. Quais os métodos empregados para resolver as questão básica do estudo?

4. Quais os resultados do estudo?

5. Qual o valor agregado ao estudo e seu resultado?

Ao procurarmos entender melhor vemos, a partir de Ferracioli (2005), a proposta que essas cinco questões transmitem, observamos que buscou-se enfatizar que a construção de novos conhecimentos se dá por uma contínua articulação entre o domínio conceitual e o domínio metodológico dos processos empregados. Mais que isso, verificamos que a essência da proposta passa principalmente pelo diálogo contínuo entre esses dois domínios.

A questão básica de um trabalho não delimita apenas seus objetivos, mas irá nortear o acionamento de áreas específicas dentro da estrutura conceitual e a delimitação do procedimento metodológico que será empregado na busca de sua resolução. Desta forma, é a atenção à questão básica que garantirá o diálogo contínuo entre o domínio conceitual Pensar - e o domínio metodológico - Fazer - para sua resolução, aspectos esses que serão explorados no estudo aqui relatado. 
Ao estabelecermos os conceitos-chaves estamos explicitando os elementos da estrutura conceitual que serão mobilizados com a finalidade de dar sentido e significado à escolha, a aplicação e a análise do evento de construção do conhecimento a ser empregado no estudo. Esta estrutura conceitual reflete, em uma ampla visão, desde o modo com que o pesquisador/estudante vê aquele assunto, até pontos específicos dentro de uma determinada área de conhecimento, explicitando teorias e princípios que serão empregados nas etapas da investigação.

Os métodos empregados são um conjunto de processos que abarcam a descrição dos eventos de construção do conhecimento, materiais e instrumentos de coleta e registros de dados, transformação destes dados para a obtenção de um resultado - asserção de conhecimento - e, a partir deste último, determinar a significância e impacto desse resultado - asserção de Valor.

Os métodos empregados são um conjunto de processos que serão realizados, desde o planejamento coleta e análise de dados e interpretação dos resultados. Esses processos abarcam a descrição dos eventos de construção do conhecimento, materiais e instrumentos de coleta de e registros de dados, transformação destes dados para se obter um resultado e interpretá-lo para se chegar na resposta a questão básica original - asserção de Conhecimento - e, a partir dessa, determinar a significância e impacto dessa resposta - asserção de Valor.

Todo esse processo foi condensado por Gowin (1981) em uma representação gráfica no formato de um Vê que acabou por dar o nome a esse ferramental, o Diagrama V que é apresentado na Figura 01. Faz-se necessário esclarecer que, segundo Gowin (1981), a construção do conhecimento pode se dar por diferentes caminhos dentro da lógica apresentada; isto é, o acionamento do domínio conceitual ou do domínio metodológico não obedecem a uma hierarquia rígida na qual um se sobrepõem ao outro. A construção do conhecimento se dá pela contínua interação entre esses domínios, onde um serve de suporte ao outro, auxiliando em sua estruturação e desenvolvimento. 


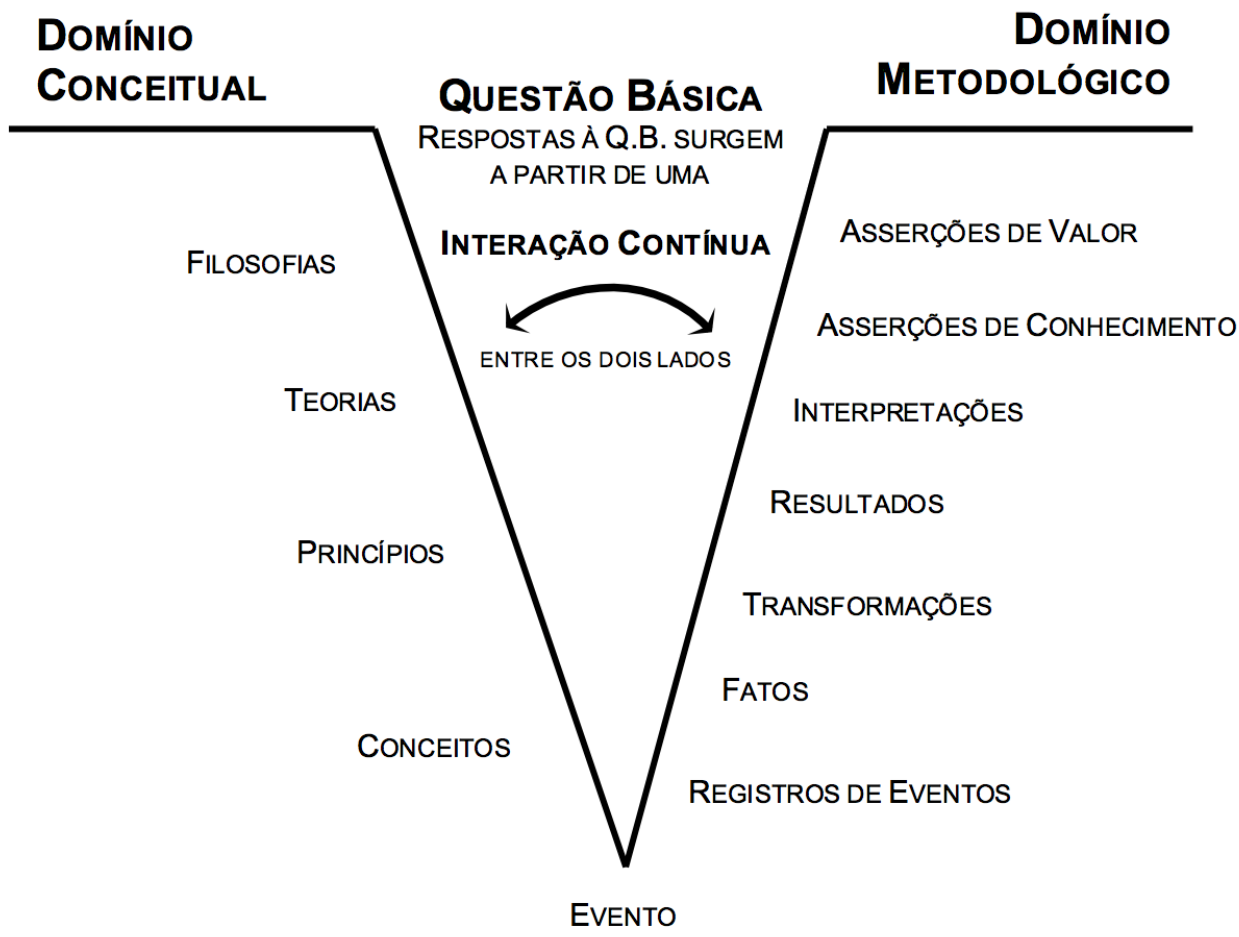

Figura 1: O V Epistemológico de Gowin (Ferracioli, 2005; 2018).

\section{II.2. O Diagrama V na Literatura}

Como apontado por Nascimento e Batista (2011), o Diagrama V é capaz de auxiliar o desenvolvimento de uma visão crítica da ciência, na medida em que proporciona ao estudante condições para que acompanhe seu próprio processo de construção dos conhecimentos; Silva \& Souza (2012) identificam o Diagrama V como facilitador da reflexão docente sobre a estrutura epistemológica do conhecimento estudado assim como seu entendimento; assim como Leboeuf \& Batista (2013) apontam que o Diagrama V pode contribuir para uma melhor mediação dos significados, tornando possível visualizar o nível de compreensão conceitual dos alunos, tornando mais profícua a interação entre alunos e professor, uma vez que promove a amplificação da discussão do tema em questão.

Articulando os resultados acima com o que nos traz Andres et al. (2007) sobre a coerência trazida pelo Diagrama V ao trabalho como um todo e a facilidade de síntese dos resultados que o mesmo proporciona nota-se o quanto o Diagrama V tem potencial para a estruturação de uma atividade experimental, em particular com a utilização da vídeo-análise no estudo de um movimento que é o foco desse estudo.

\section{II.3. Tecnologia no Ensino de Física: a vídeo-análise e o software Tracker}

Abordando a perspectiva atual onde a tecnologia perpassa pelo cotidiano de nossas vidas, Ferracioli et al (2012) aponta a necessidade de se integrar recursos tecnológicos no contexto de sala de aula sem torná-las um fim, mas sim um meio de se alcançar os objetivos educacionais. 
Araújo, Veit e Moreira (2004) em um levantamento bibliográfico sobre o uso das TICs no ensino de física encontram três diretrizes básicas para esse fim. Em primeiro lugar os estudos apontam para a necessidade do desenvolvimento e teste de estratégias instrucionais usando o computador e endereçadas às dificuldades específicas dos estudantes; em segundo lugar, exame preciso do que o estudante está aprendendo enquanto trabalha com o computador; e, em terceiro lugar, propiciar a análise de situações em ambientes reais de aprendizagem, em vez de sequências esquemáticas.

Nesse contexto, um tópico de constante dificuldade entre os estudantes é a análise e interpretação de gráficos que na física pode ser alocada no estudo da cinemática. Em relação ao exame da aprendizagem foi escolhido o Diagrama V como ferramenta de acompanhamento dos estudantes durante o desenvolvimento da atividade experimental, além de fornecer dados para análise do desenvolvimento conceitual e metodológico dos mesmos. Já para propiciar a análise de situações reais optou-se por utilizar o software gratuito Tracker que parte da gravação de fenômenos do cotidiano e facilmente realizável no contexto escolar para posterior análise, ou vídeo-análise. Para Leitão, Teixeira e Rocha (2011) a vídeo-análise consiste em fazer uma tomada de vídeo de um fenômeno simples e, na sequência, executar minucioso exame do fenômeno gravado através de ferramenta de análise de grandezas observáveis e quantificáveis da Física desse fenômeno.

O Tracker é um software de código aberto de análise de imagens e vídeos projetado por Douglas Brown, professor do Cabrillo College, Califórnia, EUA. É um software livre ligado ao projeto Open Source Physics, uma comunidade colaborativa em âmbito mundial para desenvolvimento de softwares destinados ao ensino de Física. Este software pode ser executado em qualquer sistema operacional, uma vez que depende apenas da máquina virtual Java instalada. Com o Tracker é possível realizar o estudo de movimento de objetos a partir de vídeos gravados com câmeras digitais de tablets ou celulares dos próprios estudantes, o que trás mais praticidade e acessibilidade à ferramenta. $\mathrm{O}$ Tracker pode ser baixado $^{1}$, sendo aberto à customizações que os usuários necessitem, sendo um software simples e de fácil manuseio.

A próxima seção descreve a articulação do Diagrama V com a vídeo-análise para a realização do estudo que será relatado.

\section{II.4. O Diagrama V como Estruturador da Atividade Experimental com o software Tracker}

O estudo foi estruturado de forma a permitir a orientação e acompanhamento tanto da dimensão conceitual quanto da dimensão metodológica da atividade experimental planejada. Para se atingir esse objetivo, foram construídas duas versões do Diagrama V.

Inicialmente, na busca de utilizar uma linguagem familiar aos estudantes do Ensino Médio, tomou-se como base o trabalho de Prado e Ferracioli (2014), onde os autores propõem uma adaptação do Diagrama V que traduza a estrutura Pensar-Fazer de Gowin (1981). Porém, dos elementos referentes ao domínio conceitual solicitados aos estudantes, mantivemos apenas o campo dos Conceitos, por entender que no contexto das atividades experimentais propostas com a utilização do Tracker este campo promoveria o grau de aprofundamento

\footnotetext{
${ }^{1}$ https://trackerbrasil.ct.utfpr.edu.br/?page $i d-24^{\sim}$ PginapertencenteaoprojetovinculadoUniversidadeFederaldoParandetra
} 
adequado. No entanto, assim como em Batistella (2007), foram introduzidos elementos estruturantes visando potencializar reflexões originadas pelas atividades. Dessa forma, ainda no domínio conceitual foram incluídos espaços para que houvesse os estudantes escrevessem suas Previsões sobre o fenômeno estudado e, no ao domínio metodológico, na conclusão da atividade, foi incluído espaço para que houvesse os estudantes fizessem a discussão acerca dos resultados encontrados após a realização dos experimentos levando, dessa forma, o estudante a fazer uma crítica de suas previsões e dos resultados encontrados.

Não se encontrando literatura sobre a aplicação específica do Diagrama $V$ em atividades desenvolvidas com a técnica da vídeo-análise, procurou-se observar da metodologia P-OE - Predizer-Observar-Explicar (TAO; GUNSTONE; 1999): a compreensão é de que essa abordagem alinha-se em harmonia com o processo contínuo de reflexão e interação entre o Pensar-Fazer proposto pelo Diagrama V.

A partir dessas considerações, duas versões Diagramas $\mathrm{V}$ foram produzidas para a realização da investigação, da qual o presente trabalho relata uma parcela dos resultados. A Figura 02 traz o primeiro Diagrama V-Conceitual que, com o foco na atividade experimental realizada pelos estudantes, buscava leva-los à reflexão do fenômeno estudado e dos conceitos físicos envolvidos. 
PENSAR - Domínio Conceitual

UTILIZE O VERSO DA FOLHA SE FOR NECESSÁRIO.

\begin{tabular}{|l|}
\hline CONCEITOS-CHAVE - Escreva \\
aqui os principais Conceitos \\
relacionados às Questōes Básicas. \\
\end{tabular}

C A gueda da bola e do boné são

FAZER - Domínio Metodológico

PREVISÕES

1. Qual tipo de Movimento você acha que o Boné

caindo tem:

( ) Movimento Uniforme.

( ) Movimento Uniformemente Variado.

( ) Movimento Variado Qualquer

2. Qual tipo de Movimento você acha que a Bola caindo tem:

( ) Movimento Uniforme.

( ) Movimento Uniformemente Variado.

( ) Movimento Variado Qualquer

3. Esboce como você acha que são os Gráficos da Posição, da Velocidade e da Aceleração em função

Posição, da Velocidade e da Aceleração em funçá
do Tempo para os Movimentos:

do Tempo para os Movimentos:
BOLA

1. A queda da bola e do boné são movimentos Uniformes ou

Uniformemente Variados, no intervalo filmado?

2. Ao olharmos os valores de

deslocamentos, da Velocidade e da

Aceleração, existe alguma diferença

entre a queda da Bola e do Boné? Qual?

DISCUSSÃO - Comente as diferenças DISCUSSÃO - Comente as diferenças encontradas
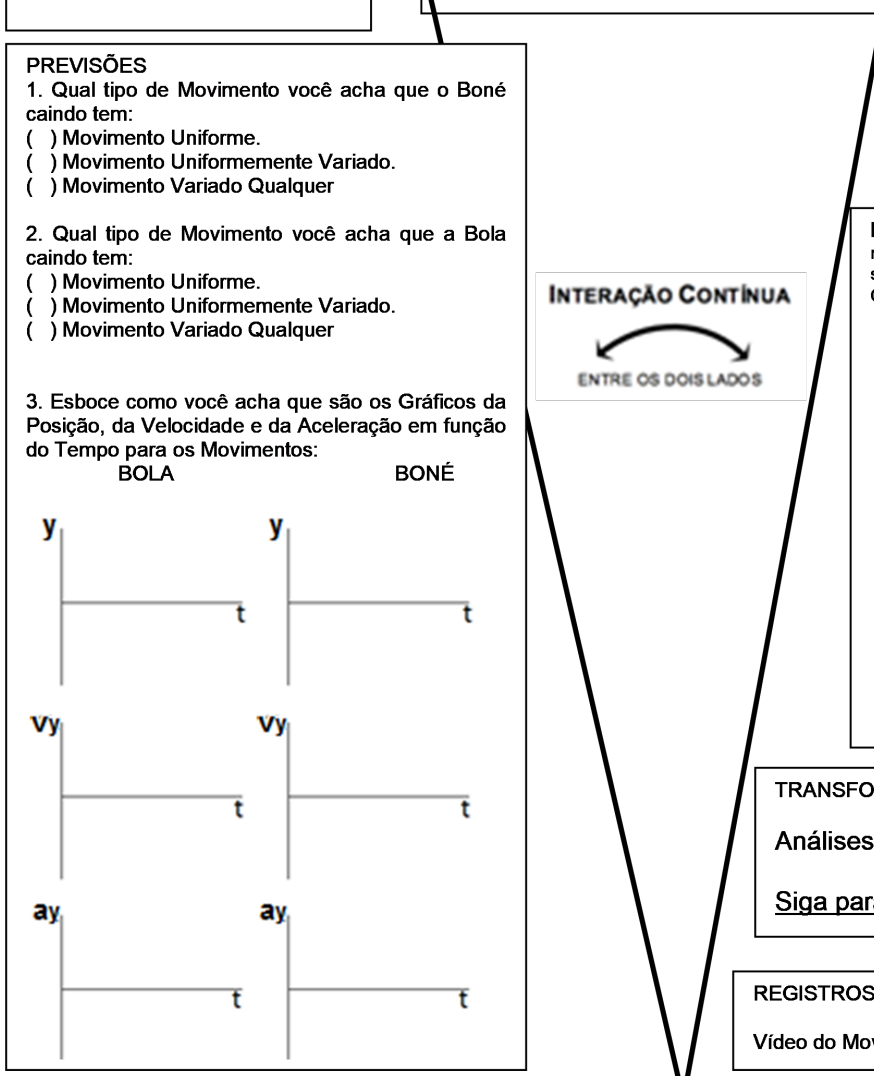

INTERPRETAÇÃO E RESULTADO - Após analisar o movimento com o software, registre aqui suas interpretaçōes sobre o movimento e a conclusão sobre as respostas das Questōes Básicas.

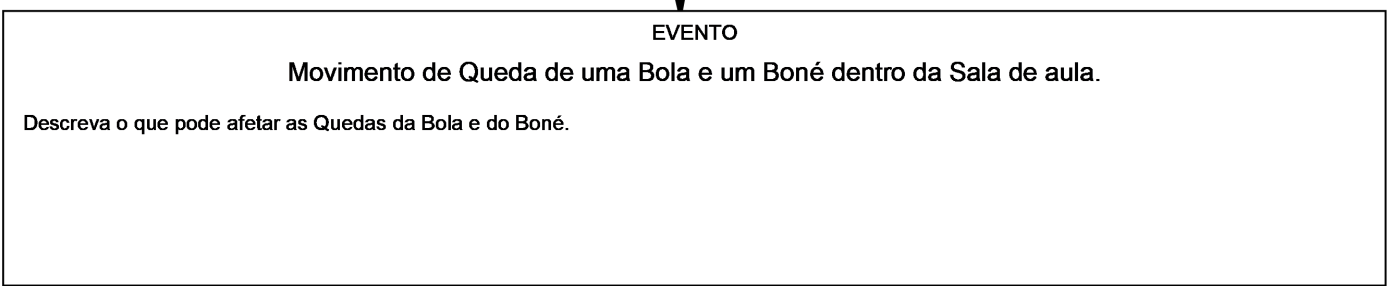

Figura 2: Diagrama V-Conceitual orientado aos conceitos da Física envolvidos no experimento.

Já a Figura 03 apresenta o Diagrama V-Experimental que, com o foco na utilização do software Tracker pelos estudantes no computador, buscava levá-los ao engajamento de uma postura atenta e reflexiva quanto aos processos de geração e análise dos gráficos. O emprego do Diagrama V- Experimental joga luz especificamente sobre o desenvolvimento de análise e amplia a reflexão durante este. 
PENSAR - Domínio Conceitual

UTILIZE O VERSO DA FOLHA SE FOR NECESSÁRIO.

FAZER - Domínio Metodolóqico

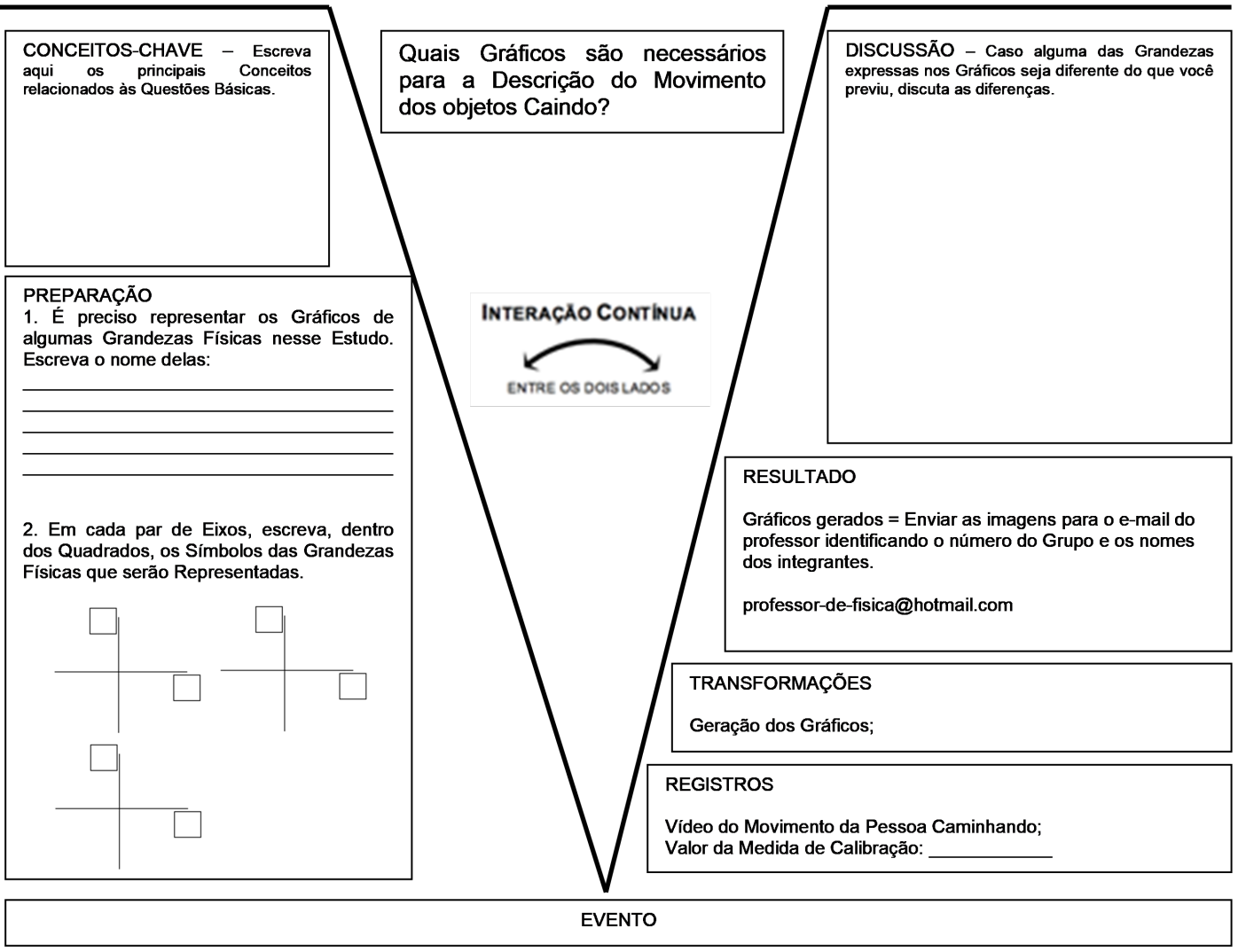

DESCREVA OS DETALHES IMPORTANTES NA GRAVAÇÃO DO VIDEO

QUAL ITEM FOI MEDIDO PARA CALIBRAÇÃO?

DESCREVA AS ETAPAS DO PROCESSO REALIZADO COM O SOFTWARE TRACKER®

Figura 3: Diagrama V-Experimental orientado à utilização do software Tracker.

Dessa forma, a estratégia foi a de utilizar inicialmente o Diagrama V-Conceitual buscando levar os estudantes a fazer uma reflexão prévia sobre suas concepções e previsões acerca do fenômeno a ser estudado; na sequência leva-los a uma detalhada análise do tipo de movimento produzido no experimento a partir dos gráficos gerados pelo software Tracker com a utilização do Diagrama V-Experimental e, finalmente, voltar a leva-los a refletir sobre as concepções e previsões por eles apresentadas a priori no Diagrama V-Conceitual, revendo seus posicionamentos iniciais e concluindo sobre todo o processo.

É importante ressaltar que os campos Transformações e Registros no o Diagrama V- 
Experimental aparecem preenchidos, pois consistem em processos que se repetem ao utilizar o software com o computador seguida pela geração dos gráficos obtidos. Como salientado por Novak e Gowin (1984), o Diagrama V não deve ser encarado como um conjunto de itens a serem preenchidos mecanicamente. Posto isso, os itens em que sempre houvesse a repetição, sem proporcionar reflexão ou evolução conceitual, foram fornecidos aos discentes após discussão prévia realizada sobre esta abordagem.

\section{Metodologia}

O objetivo do trabalho foi investigar a utilização do Diagrama V como elemento estruturador, tanto do estudo de um fenômeno físico - Diagrama V-Conceitual, quanto do procedimento de gravação desse fenômeno e vídeo-análise dessa gravação com o Tracker Diagrama V-Experimental. O estudo foi desenvolvido no contexto de um mestrado profissional em ensino de física e o presente artigo relata um dos quatro fenômenos abordados na investigação, a saber, a queda de corpos (TRABACH, 2018).

\section{III.1. Contexto do Estudo}

O estudo foi desenvolvido na escola da rede pública estadual de educação EEEFM São João Batista, localizada no município de Cariacica, pertencente à região metropolitana da Grande Vitória, ES. A localização da escola permite que muitos alunos oriundos de regiões rurais a frequentem, tornando o público mais diferenciado, em certa medida, do que tradicionalmente é encontrado em escolas da região metropolitana. A escola possui cerca de 1400 alunos, divididos em dois turnos, distribuídos entre o ensino fundamental, do $6^{\circ}$ ao $9^{\circ}$ ano e o ensino médio.

\section{III.2. Amostra}

A amostra consistiu de vinte e dois alunos de duas turmas da $1^{\text {a }}$ série do ensino médio no turno matutino. A escolha das turmas que compõem a amostra baseou-se em três critérios: coerência entre os conteúdos desenvolvidos na investigação e a determinação do currículo para cada série; o contexto do mestrado profissional em que o professor traz um problema/demanda de seu dia-a-dia para ser investigado; e o professor/pesquisador é o regente das turmas, facilitando o acesso aos alunos e a gerência das atividades realizadas com os mesmos.

Apesar de haver quatro turmas, as outras duas não apresentavam logística de horários que permitisse a completa aplicação das atividades. Além disso, vinte e dois é o número de estudantes que participaram de todas as aulas durante o estudo desenvolvido.

\section{III.3. Estruturação da Investigação}

A investigação foi estruturada em um total de 7 aulas para cada fenômeno estudado: as 4 primeiras aulas consistiram da apresentação teórica sobre o fenômeno em um modelo de aula tradicional, seguida de 3 aulas para o desenvolvimento da atividade experimental 
sobre o fenômeno com a utilização do Tracker. Ao final da quarta e última aula teórica os estudantes realizavam a gravação em vídeo do fenômeno estudado para que fosse desenvolvida a atividade experimental nas 3 aulas seguintes. O Quadro 01 traz a descrição do planejamento das 3 aulas da atividade experimental planejada com a utilização da videoanálise para estudo da queda dos corpos filmados.

Tabela

\section{III.4. A Atividade Experimental realizada sobre Queda de Corpos}

Na impossibilidade de se reproduzir um experimento em que houvesse movimentação de um objeto no vácuo, empregou-se a estratégia de analisar a queda de dois corpos com massas e formatos diferentes - uma bola e um boné - com o objetivo de evidenciar a influência do ar durante a queda dos corpos e discutir o modelo teórico para a queda livre.

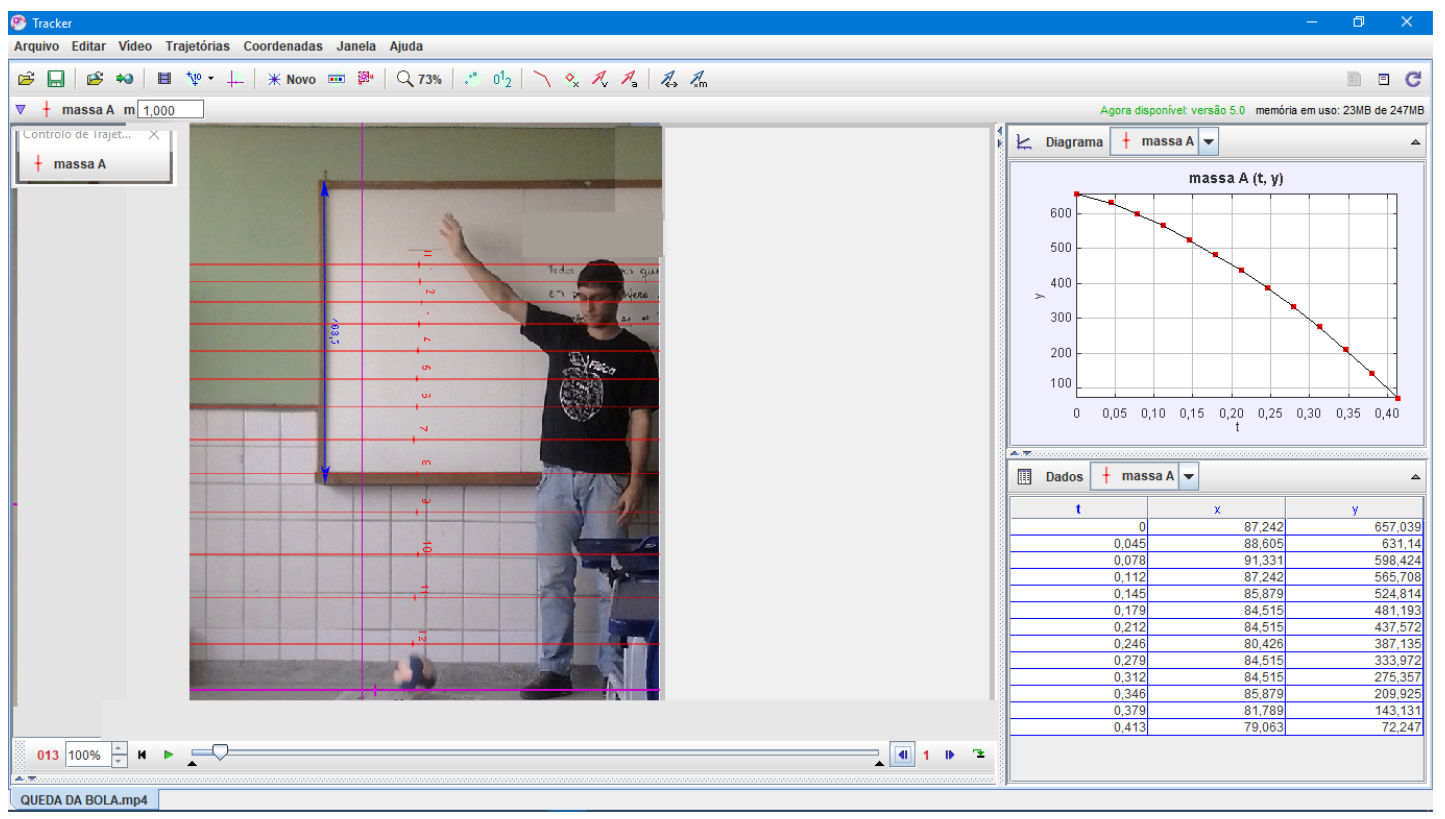

Figura 4: Tela típica do software Tracker

A Figura 04 mostra a tela típica do Tracker onde se pode observar as marcações das posições ocupadas pelo móvel - bola - sobre a imagem de seu movimento à esquerda e o gráfico e tabela de dados gerados a partir da análise do movimento à direita.

\section{III.5. Instrumento de Coleta de Dados}

Os instrumentos de coleta de dados neste estudo foram as duas versões do Diagrama V: o Diagrama V-Conceitual da Figura 02 - estruturador do estudo do fenômeno da queda dos corpos, e o Diagrama V-Experimental da Figura 03 - estruturador da atividade de gravação da queda de um boné e de uma bola e vídeo-análise dessa gravação. 


\section{ANÁLISE DOS DADOS E DISCUSSÃO}

A apresentação da análise dos dados seguirá a sequência em que as atividades foram desenvolvidas em sala de aula conforme apresentado no Quadro 01. Após estudo teórico sobre o movimento de queda de corpos que culminou com a gravação em vídeo da queda de um boné e de uma bola, os estudantes realizaram nas 3 aulas que seguiram, a atividade experimental sobre os fenômenos. O objetivo dessa sequência foi o de transmitir a maneira que a atividade foi estruturada, seguindo a perspectiva de construção do conhecimento trazida pelo Diagrama V.

Na primeira aula foi disponibilizado o Diagrama V-Conceitual para que os estudantes preenchessem à caneta os campos Conceitos-chaves, Previsões e Evento: concluído esse preenchimento, esse Diagrama V-Conceitual de cada estudante foi recolhidos. Na sequência foi disponibilizado o Diagrama V-Experimental para que os estudantes preenchessem os mesmos campos: ao final da aula esse Diagrama V-Experimental também foi recolhido. Na segunda aula os estudantes foram conduzidos ao laboratório de informática e o professor devolveu o Diagrama V-Experimental semipreenchidos na aula anterior e, após trabalharem com o Tracker os vídeos gravados, concluíram o preenchimento dos campos Evento e Discussão desse Diagrama V: ao final da aula o professor recolheu o Diagrama V-Experimental todo preenchido. Na terceira e última aula, para a finalização do estudo sobre movimento de queda livre, foram devolvidos aos estudantes seus Diagramas V-Experimental e Diagrama V-Conceitual, sendo solicitado que terminassem de preencher os campos Interpretação e Resultado e Discussão do Diagrama V-Conceitual.

A análise dos Diagramas $\mathrm{V}$ produzidos foi realizada com critérios baseados em Alvarez e Gowin (2005) no qual é adotado um escore para cada componente do Diagrama V. Para o campo Previsão foi utilizado o critério criado por e Prado (2015) e para o campo Discussão foi criado um critério seguindo a ideia desses autores de verificar a crítica do campo Previsões em relação aos resultados encontrados. Dessa forma, o Quadro 02 apresenta o roteiro da análise dos dados descrevendo cada passo desse procedimento e o Quadro 03 apresenta os critérios empregados na análise dos Diagramas V produzidos com seus respectivos escores de avaliação.

\begin{tabular}{|l|l|l|}
\hline \multicolumn{2}{|c|}{ Diagrama V-Conceitual } \\
\hline Passo 01 & Domínio Conceitual: Pensar o Experimento & análise dos campos Conceitos-chaves e Previsões \\
\hline Passo 02 & Evento & análise dos dados do campo Evento \\
\hline \multicolumn{3}{|c|}{ Diagrama V-Experimental } \\
\hline Passo 03 & Domínio Conceitual: Pensar/Organizar a Vídeo-Análise & análise dos campos Conceitos-chaves e Preparação \\
\hline Passo 04 & Evento & análise dos dados do campo Evento \\
\hline Passo 05 & Domínio Metodológico: Discussão da Vídeo-Análise & análise do campo Discussão \\
\hline \multicolumn{2}{|c|}{ Diagrama V-Conceitual } \\
\hline Passo 06 & Domínio Metodológico: Finalização do Experimento & análise dos campos Interpretação e Resultado e Discussão. Articulação dos resultados dos dois Diagramas V \\
\hline
\end{tabular}

Tabela 1: Roteiro da Análise de Dados.

\section{IV.1. Passo 01: Domínio Conceitual - Pensar o Experimento - Diagrama V-Conceitual}

A Figura 05 (a) mostra que a maioria dos estudantes apresentou uma lista com Conceitoschaves relacionados à Questão Básica e/ou Evento. Entre os conceitos levantados, aparece o de movimento que parece estar associado ao conceito velocidade, como aponta o excerto: 
- "Movimento, aceleração e posição".

O conceito gravidade chama a atenção por ser um conceito ainda não estudado até então e ter sido apontado por três estudantes, como o exemplar que segue:

- "Posição, velocidade, aceleração, gravidade, peso, distância, movimento e força do ar".

a) CONCEITOS-CHAVE - DIAGRAMA V-CONCEITUAL

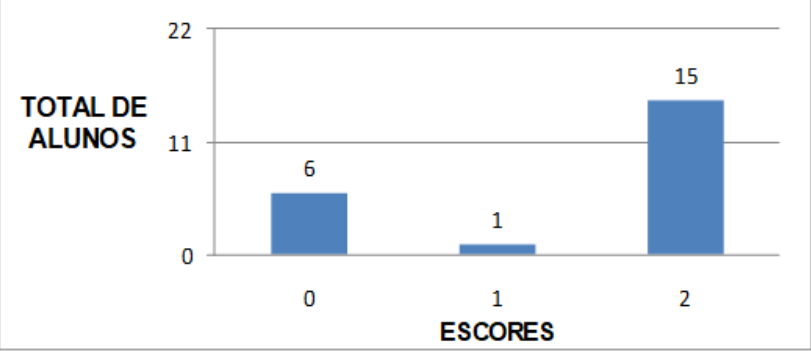

b) PREVISÖES - DIAGRAMA V-CONCEITUAL

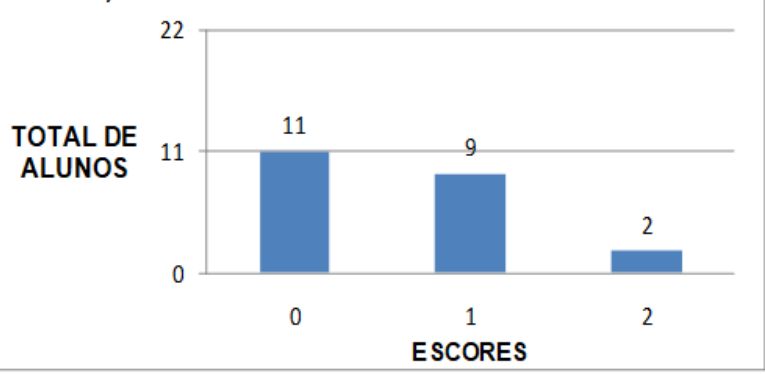

Figura 5: Conceitos-Chaves e Previsões a partir do Diagrama V-Conceitual do Estudo do Movimento de Queda de Corpos.

Entre os seis estudantes que não identificaram conceitos, dois estudantes deixaram o campo em branco e um escreveu "Não sei". Dos três estudantes restantes predominam apontamentos em que há o levantamento de questões complementares ou inferências acerca do movimento mas que não dizem respeito diretamente à Questão Básica e/ou Evento.

A Figura 05 (b) mostra as Previsões escritas pelos estudantes ao responder sobre o tipo de movimento apresentado e a forma que teriam os gráficos das grandezas cinemáticas. $\mathrm{O}$ procedimento de análise foi o de verificar se havia consistência nas respostas ao se contrapor o tipo de movimento previsto com os esboços gráficos desenhados pelos estudantes. A análise revela que dos 22 estudantes, somente dois alunos indicaram o tipo correto de movimento representando a maioria dos esboços gráficos de maneira condizente. Dos demais, 9 indicaram corretamente o tipo de movimento, mas a maioria dos esboços gráficos apresentados não condizia com o tipo de movimento assinalado e 11 estudantes inferiram incorretamente o tipo de movimento, indicando se tratar de movimento uniforme e sem apresentar esboços gráficos. É importante relatar que o esboço gráfico para as posições em função do tempo foi representado erroneamente por todos os estudantes. Esse panorama revela que o conhecimento prévio à realização do estudo do movimento de queda de corpos explicitado pelos estudantes apresenta a identificação de diversos Conceitos-chaves associados corretamente ao experimento estudado. No entanto, este conhecimento prévio mostra-se incompleto para inferir sobretudo, na representação gráfica das grandezas cinemáticas associadas ao movimento. 


\begin{tabular}{|c|c|c|c|c|c|c|}
\hline \multirow{2}{*}{\multicolumn{2}{|c|}{ QUESITOS }} & \multicolumn{5}{|c|}{ ESCORES } \\
\hline & & 0 & 1 & 2 & 3 & 4 \\
\hline \multirow{5}{*}{ 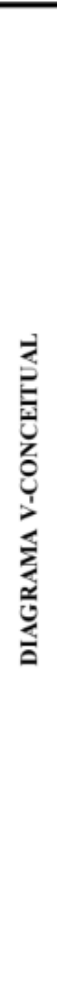 } & $\begin{array}{l}\text { Conceitos- } \\
\text { chave }\end{array}$ & $\begin{array}{l}\text { Nenhum Conceito é } \\
\text { identificado }\end{array}$ & \begin{tabular}{|c|} 
Conceitos são \\
identificados, mas não \\
estão relacionados com a \\
Questão foco e/ou os \\
Eventos \\
\end{tabular} & $\begin{array}{c}\text { Conceitos são } \\
\text { identificados e estão } \\
\text { relacionados com a } \\
\text { Questão foco e/ou os } \\
\text { Eventos } \\
\end{array}$ & - & - \\
\hline & Previsões & $\begin{array}{c}\text { Conceitos são identificados } \\
\text { e estão relacionados com a } \\
\text { Questão foco e/ou os } \\
\text { Eventos }\end{array}$ & $\begin{array}{c}\text { Identifica corretamente o } \\
\text { tipo de movimento MAS } \\
\text { a forma da maioria dos } \\
\text { esboços dos gráficos NÃo } \\
\text { condiz com o tipo de } \\
\text { movimento identificado }\end{array}$ & $\begin{array}{c}\text { Identifica corretamente o } \\
\text { tipo de movimento } \mathrm{e} \text { a } \\
\text { forma da maioria dos } \\
\text { esboços dos gráficos } \\
\text { condiz com o tipo de } \\
\text { movimento identificado }\end{array}$ & - & - \\
\hline & Evento & $\begin{array}{c}\text { Apresenta } \\
\text { fatores/conceitos sem } \\
\text { relação com a Questão foco } \\
\text { e/ou Evento }\end{array}$ & \begin{tabular}{|c|} 
Apresenta \\
fatores/conceitos \\
relacionados com a \\
Questão foco e/ou Evento \\
sem descrevê-los \\
\end{tabular} & $\begin{array}{c}\text { Apresenta } \\
\text { fatores/conceitos } \\
\text { relacionados com a } \\
\text { Questão foco e/ou Evento } \\
\text { descrevendo-os de } \\
\text { inadequadamente }\end{array}$ & \begin{tabular}{|c|} 
Apresenta \\
fatores/conceitos \\
relacionados com a \\
Questão foco e/ou \\
Evento, descrevendo-os \\
adequadamente
\end{tabular} & - \\
\hline & $\begin{array}{l}\text { Interpretação } \\
\text { e Resultado }\end{array}$ & $\begin{array}{l}\text { Nenhuma Interpretação e } \\
\text { Resultado é apresentado }\end{array}$ & \begin{tabular}{|c|} 
São apresentados \\
Interpretação e Result ado \\
relacionados com a \\
Questão foco e/ou o \\
Evento de forma \\
inadequada \\
\end{tabular} & \begin{tabular}{|c|} 
São apresentados \\
Interpretação e Resultado \\
relacionados com a \\
Questão foco e/ou o \\
Evento de forma \\
inadequada \\
\end{tabular} & - & - \\
\hline & Dicussão & $\begin{array}{c}\text { Nenhuma Discussão é } \\
\text { apresentada }\end{array}$ & \begin{tabular}{|c} 
Discussão é apresentada \\
relacionando as Previsões \\
com Interpretação e \\
Resultado de forma \\
inadequada
\end{tabular} & \begin{tabular}{|c} 
Discussão é apresentada \\
relacionando as Previsões \\
com Interpretação e \\
Resultado de forma \\
adequada
\end{tabular} & - & - \\
\hline \multirow{4}{*}{ 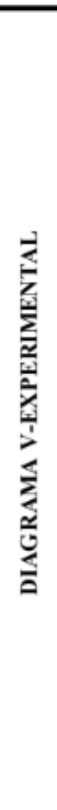 } & $\begin{array}{l}\text { Conceitos- } \\
\text { chave }\end{array}$ & $\begin{array}{l}\text { Nenhum Conceito é } \\
\text { identificado }\end{array}$ & \begin{tabular}{|c|} 
Conceitos são \\
identificados, mas não \\
estão relacionados com a \\
Questão foco e/ou os \\
Eventos \\
\end{tabular} & $\begin{array}{c}\text { Conceitos são } \\
\text { identificados e estão } \\
\text { relacionados com a } \\
\text { Questão foco e/ou os } \\
\text { Eventos }\end{array}$ & - & - \\
\hline & Preparação & $\begin{array}{l}\text { Identifica incorretamente } \\
\text { as grandezas fisicas e/ou as } \\
\text { representam } \\
\text { inadequadamente nos } \\
\text { quadrados dos gráficos }\end{array}$ & \begin{tabular}{|c|} 
Identifica corretamente a \\
maioria das grandezas \\
fisicas e/ou as \\
representam \\
adequadamente em sua \\
maioria nos quadrados dos \\
gráficos \\
\end{tabular} & \begin{tabular}{|c} 
Identifica corretamente as \\
grandezas fisicas e/ou as \\
representam \\
adequadamente nos \\
quadrados dos gráficos \\
\end{tabular} & - & 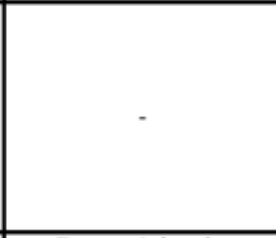 \\
\hline & Evento & $\begin{array}{c}\text { Evento é descrito de forma } \\
\text { totalmente incoerente }\end{array}$ & $\begin{array}{l}\text { Evento é descrito } \\
\text { identificando apenas o } \\
\text { item de calibração } \\
\text { utilizado }\end{array}$ & $\begin{array}{c}\text { Evento é descrito } \\
\text { identificando o item de } \\
\text { calibração utilizado e } \\
\text { incluindo detalhes } \\
\text { importantes na gravação. }\end{array}$ & $\begin{array}{c}\text { Evento é descrito } \\
\text { identificando o item de } \\
\text { calibração utilizado e } \\
\text { incluindo etapas do } \\
\text { processo de utilização do } \\
\text { Tracker }\end{array}$ & $\begin{array}{c}\text { Evento é descrito } \\
\text { identificando o item de } \\
\text { calibração utilizado e } \\
\text { incluindo detalhes } \\
\text { importantes na gravação e } \\
\text { etapas do processo de } \\
\text { utilização do Tracker }\end{array}$ \\
\hline & Dicussão & $\begin{array}{c}\text { Nenhuma Discussão é } \\
\text { apresentada }\end{array}$ & $\begin{array}{c}\text { Discussão é apresentada } \\
\text { relacionando as Previsões } \\
\text { com Interpretação e } \\
\text { Resultado de forma } \\
\text { inadequada }\end{array}$ & $\begin{array}{c}\text { Discussão é apresentada } \\
\text { relacionando as Previsões } \\
\text { com Interpretação e } \\
\text { Resultado de forma } \\
\text { adequada }\end{array}$ & - & - \\
\hline
\end{tabular}

Tabela 2: Caption

\section{IV.2. Passo 02: Evento - Diagrama V-Conceitual}

O campo Evento solicitou que os estudantes descrevessem os fatores que poderiam afetar o movimento após o visualizarem, mas antes de aplicar a vídeo-análise. Observa-se que 19 estudantes apontaram fatores que poderiam influenciar o movimento, sendo que 
destes apenas 6 fizeram alguma descrição da forma como estes fatores influenciam no movimento as quais foram consideradas adequadas. Os principais elementos evocados nos apontamentos mostrados na Figura 06, mesmo que sem apresentar uma explicação de como interferem no movimento, foram do meio, como a resistência do ar e gravidade, mas também propriedades ligadas aos objetos e à situação específica como massa e posição inicial.

O conceito vento chama a atenção por parecer apontar que está associado ao conceito resistência do ar na resposta dos seis estudantes, como no excerto:

- "O vento e a gravidade".

Apenas três estudantes apresentaram fatores sem relação com a Questão-Básica e/ou o Evento.

O conhecimento explicitado é prévio ao processo de análise realizado e mostra que, apesar da grande maioria ser capaz de identificar fatores que podem influir no experimento estudado, apenas uma pequena parte tentou e conseguiu ir além da mera identificação dos fatores e descreveu como os mesmos interferiam no movimento.

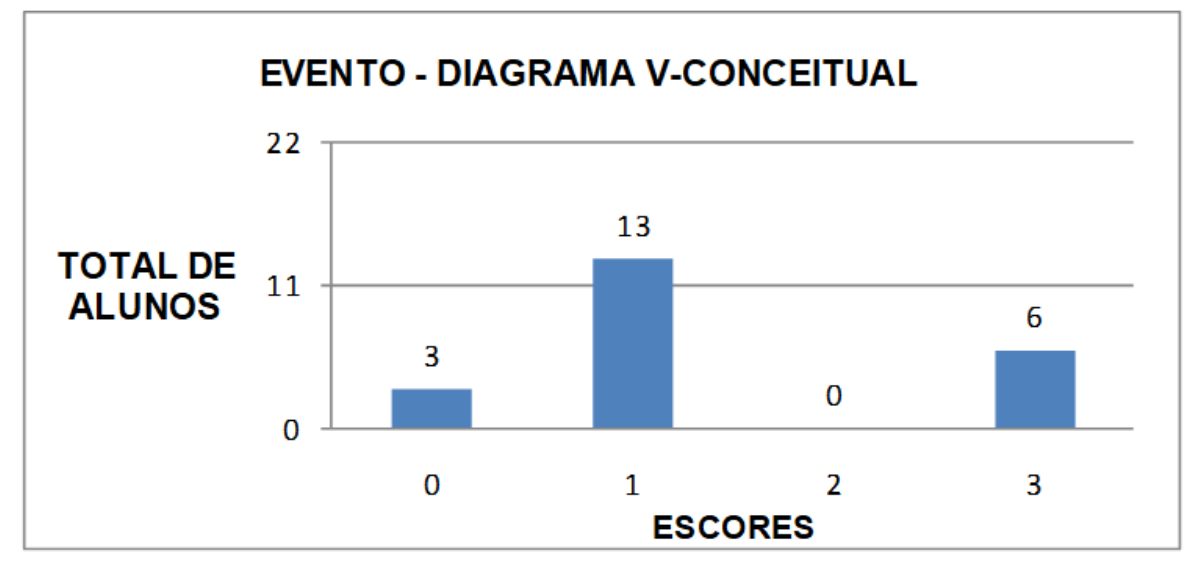

Figura 6: Eventos a partir do Diagrama V-Conceitual do Estudo do Movimento de Queda de Corpos.

\section{IV.3. Passo 03: Domínio Conceitual - Pensar a Vídeo-Análise - Diagrama V-Experimental}

Analisando agora os campos do Diagrama V-Experimental, a Figura 07(a) mostra que 18 dos 22 estudantes que indicaram conceitos chaves envolvido no fenômeno e apenas 4 estudantes não apontaram conceito algum. Apesar de 5 dos 18 estudantes apontarem conceitos sem relação com a Questão-Básica e/ou o Evento, 13 o fizeram de maneira adequada, como no excerto:

- "Posição, velocidade, aceleração, gráfico, tempo e movimento"

Neste apontamento é possível destacar que é identificado gráfico como um conceito concernente à parte da análise experimental realizada com o Tracker. 
A Figura 07(b) mostra que 21 estudantes identificaram corretamente as grandezas que deveriam ser expressas nos gráficos, sendo que 11 identificaram corretamente, também, toda a simbologia empregada pelo software Tracker para a representação das mesmas.
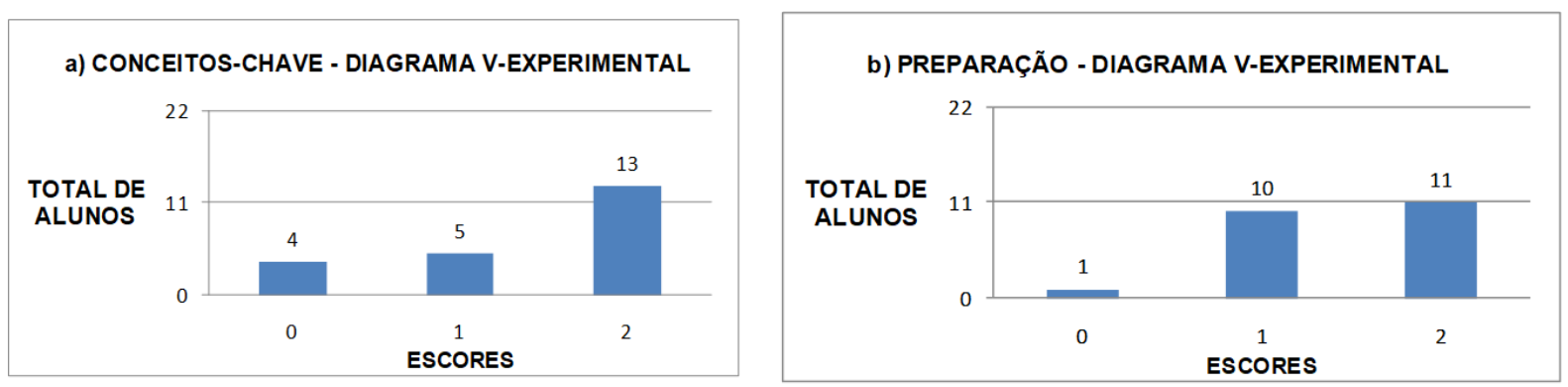

Figura 7: Conceitos-Chaves e Preparação a partir do Diagrama V-Experimental do Estudo do Movimento de Queda de Corpos.

Assim como nas subseções anteriores, os estudantes deveriam apresentar nesse momento um conhecimento prévio à aplicação da vídeo-análise e, novamente, a maioria dos estudantes conseguiu identificar Conceitos-chaves coerentes com a Questão Básica e/ou com o Evento. Além disso, praticamente todos os estudantes identificaram corretamente as grandezas físicas que seriam representadas nos gráficos e metade destes também identificaram corretamente os símbolos empregados pelo Tracker para representar estas grandezas.

\section{IV.4. Passo 04: Evento - Diagrama V-Experimental}

O campo Evento do Diagrama $V$-Experimental solicita ao estudante que explicite os aspectos práticos realizados e ligados à aplicação da técnica de vídeo-análise. Este se divide em três blocos: detalhes da gravação do vídeo; calibração da medida de grandeza e utilização do software Tracker.

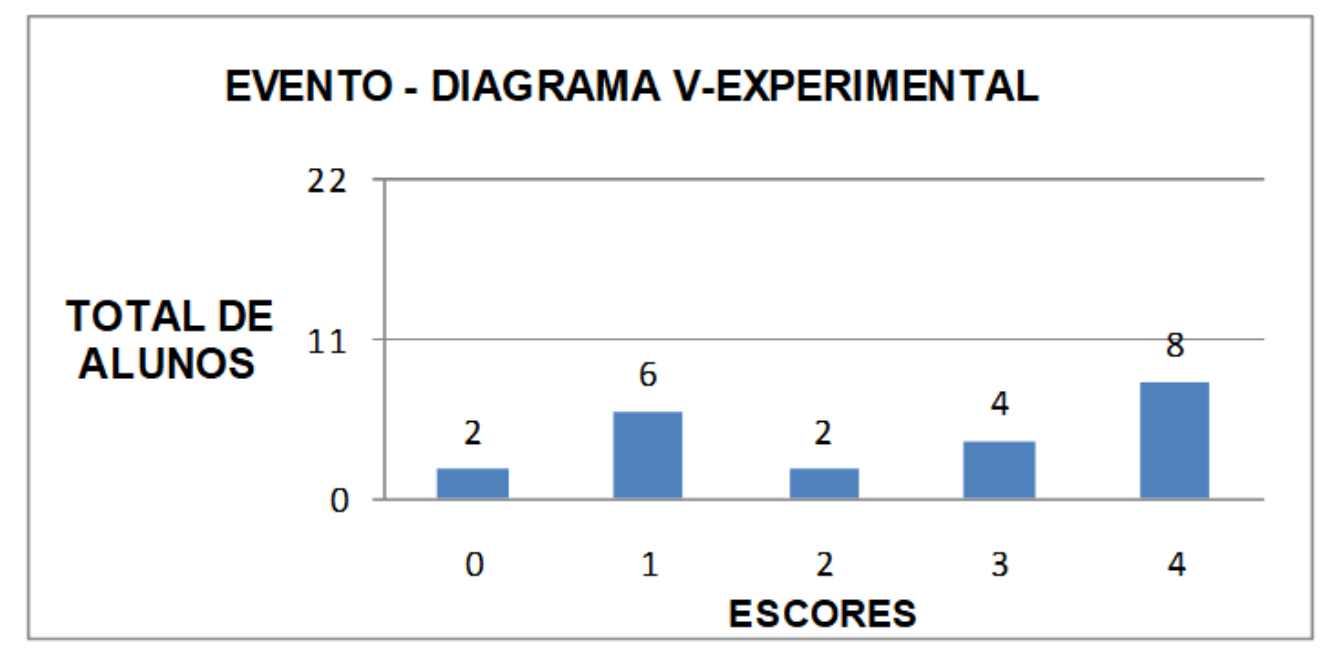

Figura 8: Eventos a partir do Diagrama V-Experimental do Estudo do Movimento de Queda de Corpos

A Figura 08 revela que do total de 22 estudantes, 14 identificaram corretamente o item de calibração e apresentaram detalhes técnicos importantes em relação à vídeo-análise ligados à 
gravação do vídeo do movimento e à utilização do software Tracker, separadamente. Desse total, 8 estudantes apresentaram respostas consideradas completas, apontando detalhes importantes da gravação do vídeo, identificando o item de calibração, e do emprego do Tracker, como mostra o excerto que segue:

- "Posicionar a câmera de modo que pegue todo o quadro e o movimento dos corpos e que os corpos estejam na mesma altura; $O$ item de calibração foi a altura do quadro; Colocamos o vídeo, calibramos o item de calibração, geramos os gráficos, coletamos os gráficos e tivemos os resultados".

Do restante desses 14 estudantes, 4 descreveram detalhes apenas do uso do Tracker e dois que apenas descreveram os detalhes de gravação do vídeo para análise. Pode-se ver, ainda, que 6 estudantes apenas identificaram o item de calibração, não descrevendo os processos de gravação e nem de utilização do software Tracker, enquanto os dois estudantes restantes apresentaram eventos totalmente incoerentes. Um dos objetivos do Diagrama V é, assim como visto em Pacheco \& Damasio (2009), promover a reflexão sobre a prática experimental e propiciar que o estudante tome consciência do sentido que há nos procedimentos que realiza durante a realização do experimento e de sua análise. Assim, a Figura 08 evidencia que houve vários níveis de assimilação da dinâmica de realização do experimento. Observa-se que menos da metade dos estudantes teve uma assimilação dos procedimentos contemplando todos os aspectos da execução desde a gravação até a análise do vídeo do movimento utilizando o Tracker. Contudo, a grande maioria demonstrou assimilar aspectos gerais relativos ao processo de análise do experimento.

\section{IV.5. Passo 05: Domínio Metodológico - Discussão Vídeo-Análise - Dia- grama V-Experimental}

A Figura 09 revela que 21 estudantes da amostra apresentaram algum tipo de discussão, sendo que, dentre estes, 18 respostas relacionavam de forma adequada a Preparação com o Resultado, enquanto 3 estudantes se equivocaram e utilizaram o campo para apresentar o Resultado. Os excertos que seguem ilustram discussões apresentadas de maneira adequada.

- "As grandezas que eu imaginava ocorreram, só que na hora de por os sinais ocorreu um erro nos gráficos".

- “Bom, a respeito das grandezas físicas eu previ certo, só que a posição eu coloquei x ao invés de $\mathrm{y}^{\prime \prime}$. 


\section{DISCUSSÃO - DIAGRAMA V-EXPERIMENTAL}

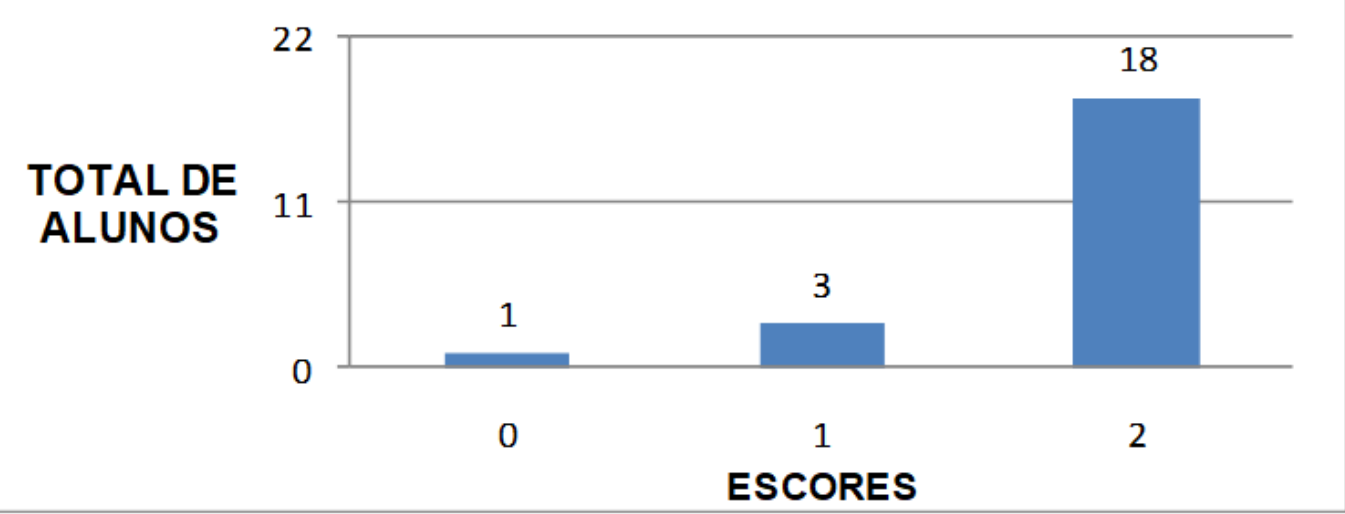

Figura 9: Discussão a partir do Diagrama V-Experimental do Estudo do Movimento de Queda de Corpos.

Ao observarmos esse elevado número de estudantes que refletiram sobre suas previsões e o resultado obtido, verificamos que, assim como relatado por Nascimento \& Batista (2011), a estruturação do Diagrama V auxilia o estudante a desenvolver uma visão crítica, na medida em que proporciona condições para que ele acompanhe seu próprio processo de construção do conhecimento.

A próxima seção finaliza o processo de análise, apresentando os resultados dos campos Interpretação e Resultado e Discussão do Diagrama V-Conceitual, após os estudantes terem realizado os processos no laboratório de informática norteados pelo Diagrama VExperimental. Ao retomarem o Diagrama V-Conceitual na sala de aula, os estudantes foram levados a verificar a crítica do campo Previsões em relação aos resultados como sugerido por Alvarez e Gowin (2005), ou seja, novamente contrapor criticamente suas hipóteses iniciais com o resultado obtido e finalizar a atividade experimental proposta. Além disso, esta seção irá apresentar o resultado do diálogo entre os resultados obtidos com os dois Diagramas empregados.

\section{IV.6. Passo 06: Domínio Metodológico - Finalização do Experimento - Diagrama V-Conceitual}

A finalização do experimento se dá com a volta ao Diagrama V-Conceitual para a análise dos campos Interpretação e Resultado e Discussão e articulação com os resultados da análise do Diagrama V-Experimental. A Figura 10 (a) mostra que 20 estudantes apresentaram alguma Interpretação e Resultado, sendo que, dentre estes, 9 alinharam adequadamente seus apontamentos com a Questão Básica e/ou ao Evento como destaca o excerto:

- "1. Movimento Uniformemente Variado. 2. Existe uma diferença na aceleração devido a resistência do ar".

Os outros 11 alunos que apresentaram alguma Interpretação e Resultado o fizeram de forma inadequada, enquanto que apenas dois alunos não apresentaram nenhum apontamento. 


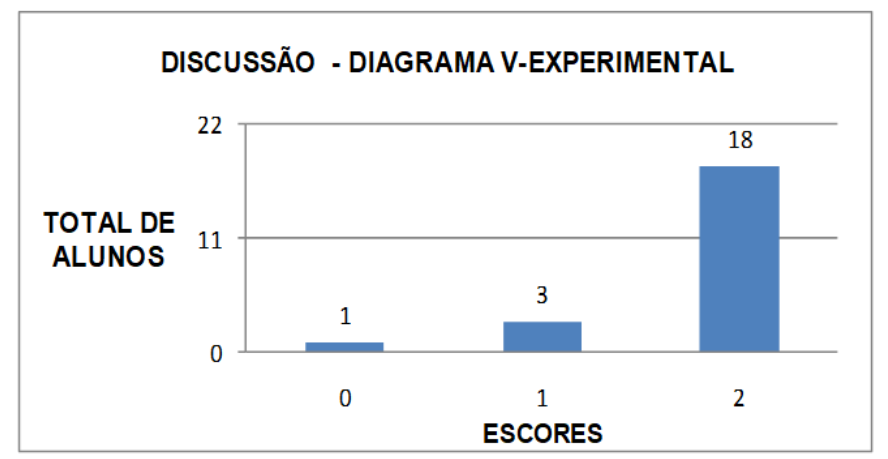

b) PREPARAÇÃO - DIAGRAMA V-EXPERIMENTAL

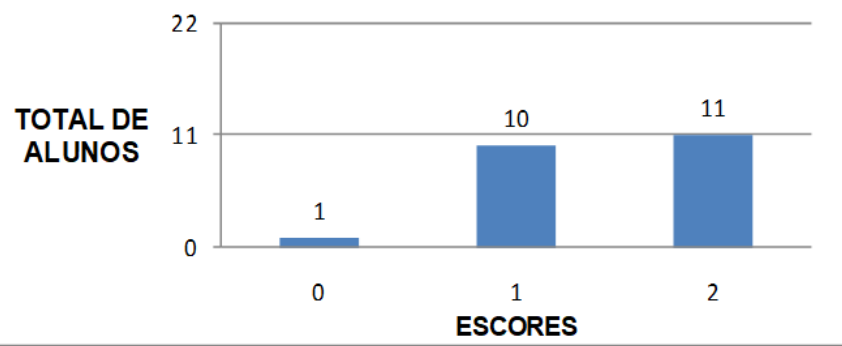

Figura 10: Interpretação e Resultado e Discussão a partir do Diagrama V-Conceitual do Estudo do Movimento de Queda de Corpos.

A Figura 10(b) evidencia que 20 estudantes realizaram uma contraposição entre Previsões e Interpretação e Resultado de maneira adequada, alguns apontando diferenças nos tipos de movimento e outros na forma dos gráficos de maneira geral, como nos excertos:

- "Nos gráficos da Bola, a posição teve uma forma mais contínua e o do boné se alterou na queda devido a interferência do ar, e a posição foi variada e não contínua".

- "Eu encontrei diferença no gráfico de Posição por que eu previ que ele iria ser constante, mas ele foi diminuindo".

- "Os gráficos não estão de acordo com o Movimento, mas é uniformemente Variado, tanto o boné quanto a bola".

Leboeuf \& Batista (2013) relatam que o Diagrama V pode contribuir para uma melhor mediação dos significados, tornando possível visualizar o nível de compreensão conceitual dos alunos, mesmo quando apresentados com certa pobreza de significados. A Figura 10 (a) revela que a preponderante maioria dos estudantes, com exceção de dois, apresentou Interpretação e Resultado relacionado com a Questão Básica e/ou o Evento, mesmo que apenas metade o fazendo de forma adequada.

Os resultados do presente estudo revelam que o Diagrama $\mathrm{V}$ proporcionou aos estudantes condições para que acompanhasse seu próprio processo construção de conhecimento, como revelado pela Figura 10(b), em que, novamente, quase que a totalidade dos estudantes contrapuseram e relacionaram de maneira coerente suas previsões com os resultados da análise realizada.

Conforme apontado anteriormente, a Questão Básica do Diagrama V norteia o acionamento de áreas específicas dentro da estrutura conceitual e a delimitação do procedimento metodológico que será empregado na busca de sua resolução. Desta forma, a atenção à Questão Básica garante o diálogo contínuo entre o Domínio Conceitual - Pensar - e o Domínio Metodológico - Fazer - para se chegar a uma resposta, ou seja, finalizar o processo de construção de conhecimento sobre o tema abordado. A observação de como os estudantes realizaram e como finalizaram a análise do movimento, evidencia-se a presença de elementos das dimensões Conceitual e Metodológica do processo realizado em suas conclusões e, mesmo em seus apontamentos, durante as várias etapas do processo de análise. 


\section{CONSIDERAÇÕES FINAIS}

Assim como a evolução do conhecimento, o Diagrama V (GOWIN, 1981; FERRACIOLI, 2005; 2018) fornece uma rotina de reconstrução, orientando a adaptação a realidades diferentes daquelas em que fora aplicado inicialmente. Os Diagramas V estruturados e aplicados neste estudo apresentaram aspectos também levantados por Andres et al. (2007), mostrando-se eficazes na busca de fornecer diretrizes para que os estudantes mantivessem o foco na atividade experimental e pudessem refletir sobre os processos realizados, bem como facilitando a síntese dos resultados e, dessa forma, permitindo a construção de coerência ao longo do trabalho como um todo.

Na mesma perspectiva relatada por Wesoly \& Costa (2008) e Prado \& Ferracioli (2017), à medida que os estudantes se familiarizaram com o Diagrama $\mathrm{V}$ e com as etapas de análise do experimento, eles incorporaram e passaram a utilizar o Diagrama V de maneira natural como qualquer outro instrumento com o qual já tivessem trabalhado anteriormente, entendendo suas partes e respeitando a linha crescente na construção dos conceitos.

A estruturação do Diagrama V-Conceitual e do Diagrama V-Experimental partiu da proposta de levar o estudante a engajar em um processo de atenção e reflexão durante a realização do experimento, evitando, dessa forma, o desenvolvimento da atividade de forma mecânica e não e significativa conforme apontado por Novak e Gowin (1984). Dessa forma, considerando o objetivo desse estudo que foi o de investigar a utilização do Diagrama V como elemento estruturador, tanto do estudo de um fenômeno - Diagrama V-Conceitual, quanto da gravação desse fenômeno e vídeo-análise dessa gravação com o Tracker - Diagrama V-Experimental, foi possível observar que esta estrutura foi exitosa na medida que observou-se uma maior atenção e cuidado, por parte dos estudantes, durante a realização das atividades no laboratório de informática. Além disso, conforme os procedimentos no laboratório tornaram-se rápidos e imediatos na medida em que os alunos ganharam habilidade em sua realização, o uso do Diagrama V proporcionou uma ocupação do tempo e a manutenção do foco dos estudantes durante toda a aula, buscando respostas para a análise física dos movimentos, conforme relatado por Capelleto (2009) e Pereira \& Ferracioli (2017).

Por outro lado, a proposta de utilizar o Diagrama V como instrumento de coleta de dados pode ser classificada, em linhas gerais, como eficiente, abrangente e organizada, $\mathrm{o}$ que já se esperava após a leitura de Andrés et al. (2007) que afirma que o Diagrama V é uma ferramenta orientadora para o trabalho cooperativo, que permite a troca de significados pelos estudantes e para que entendam que existe uma relação intrínseca e inseparável entre os aspectos teórico e metodológico no método científico.

Apesar de cada campo do Diagrama V parecer com uma questão aberta, o que poderia, em outras situações, tornar difíceis o preenchimento e a posterior análise do mesmo, foi possível identificar que os princípios que embasavam o conteúdo e a estrutura do Diagrama $\mathrm{V}$ também permitiram que o preenchimento fosse realizado de maneira objetiva e com uma consequente lógica para as discussões e reflexões sobre o realizado. Essa sistemática, também, refletiu no processo de avaliação dos estudantes: através dos Diagramas $\mathrm{V}$ preenchidos e dos critérios de avaliação dos mesmo, esses constituíram-se em critérios claros para a avaliação do desenvolvimento dos estudantes. 
Esse tipo de atividade experimental agrega outra dimensão de analise ao repertório dos alunos, ou seja, é uma atividade que supera o atividade experimental tradicional, associando-se ao uso da informática, um ponto importante de ser explorado dentro da pesquisa em Ensino de Física.

Os resultados aqui relatados apontam que a utilização do Diagrama V como elemento estruturador e instrumento de coleta de dados em uma atividade experimental em aulas de Física empregando a técnica de vídeo-análise através do software Tracker com estudantes do primeiro ano do Ensino Médio revelou-se oportuna e eficiente: tanto para levar os estudantes ao engajamento em uma postura atenta e reflexiva de articulação entre o pensar e o fazer em uma atividade experimental quanto para auxiliar o professor no processo de avaliação desses estudantes (FERRACIOLI, 2005; 2018). A próxima etapa é ampliar essa investigação para distintas áreas da Física na busca de sustentação para a ampliação desses resultados.

\section{AGRADECIMENTO}

Trabalho parcialmente financiado pelo CNPq, CAPES, FAPES-ES e FACITEC/PMV Fundo de Apoio à Ciência e Tecnologia do Conselho Municipal de Ciência e Tecnologia do Município de Vitória, ES.

\section{REFERÊNCIAS}

ANDRÉS, M.; MENESES, J.; PESA, M. (2006). Efectividad meta cognitiva de La heurística V de Gowin em trabajos de laboratório centrados em la resolución de situaciones problemáticas. Memorias Del V Encuentro sobre Aprendizaje Significativo. Madrid. Publicada em Indivisa: Boletín de Estudios e Investigación, 2007, N extraordinário. PP. 203-216.

ARAÚJO, I. S., VEIT, E. A.; MOREIRA, M. A. (2004) Atividades de Modelagem Computacional no Auxílio à Interpretação de Gráficos da Cinemática. Revista Brasileira de Ensino de Física, v. 26, n 2, p. 179-184.

BATISTA, I. L; NASCIMENTO, E. G. União da História da Ciência com o V de Gowin: um estudo na formação de professores nas séries iniciais. Revista Brasileira de Pesquisa em Educação em Ciências. Vol. 11 No 2, 2011.

BATISTELLA, C.A.R. Atividades de Ótica Exploradas no Ensino Médio através de Reflexões Epistemológicas com o Emprego do $V$ de Gowin. Dissertação (mestrado em Ensino de Física Programa de Pós-Graduação em Ensino de Física- Instituto de Física- UFRGS), Porto Alegre, 2007.

BORGES, A. T. Novos rumos para o laboratório escolar de ciências. Caderno Brasileiro de Ensino de Física 19(3), 291-313. 2002.

CAPPELLETO, E. O VÊ de Gowin Conectando Teoria e Experimentação em Física Geral: Questões Didáticas, Metodológicas e Epistemológicas Relevantes ao Processo. Dissertação de Mestrado - 
Programa de Pós-Graduação em Ensino de Física, Instituto de Física, Universidade Federal do Rio Grande do Sul, Porto Alegre, 2009.

FERRACIOLI, L. O V epistemológico como Instrumento Metodológico para o processo de Investigação. 2005, Revista Didática Sistêmica, Fundação Universidade Federal do Rio Grande.

FERRACIOLI, L.; GOMES, T. MARQUES, R.; MULINARI, M.H.; OLIVEIRA, R.R.; CAMILETTI, G.G.; MORELATO, F.; FEHSENFELD, K.; VERBENO, C.H. Ambientes de Modelagem Computacional no Aprendizado Exploratório de Física. Caderno Brasileiro de Ensino de Física, v.29, n.2 Especial, p. 679-707, 2012.

FERRACIOLI, L. O Diagrama V no Ensino Experimental. 2018, Publicação Interna do ModeLab. Departamento de Física, Universidade Federal do Espírito Santo.

GOWIN, D.B.(1981) Educating. Ithaca, Cornel University Press.

GOWIN, D.B.; ALVAREZ, M.C. The Art Educating with V Diagrams. Cambridge University Press, New York, 2005.

LEBOEUF, H. .A; BATISTA, I. L. O uso do " $v$ " de Gowin na formação docente em ciências para os anos iniciais do ensino fundamental. Investigações em Ensino de Cências. V. 18, n.3, 2013. P. 697-721.

PRADO, R. T.; FERRACIOLI, L. Utilização do Diagrama $V$ em Experimentos de Física em Sala de Aula de Ensino Médio. In: $5^{\circ}$ ENCONTRO NACIONAL DE APRENDIZAGEM SIGNIFICATIVA, 2014, Belém. Anais $5^{\circ}$ Encontro Nacional de Aprendizagem Significativa, Belém PA. ENAS, 2014.

PRADO, R. T. A Utilização do Diagrama $V$ em Atividades Experimentais de Física em Sala de Aula de Ensino Médio. 2015. Dissertação de Mestrado - Centro de Ciências Exatas, Universidade Federal do Espírito Santo, Vitória, 2015.

PRADO, R. T.; FERRACIOLI, L. (2017) UTILIZAÇÃO DO DIAGRAMA V EM ATIVIDADES EXPERIMENTAIS DE MAGNETISMO EM SALA DE AULA DE ENSINO MÉDIO, Revista do Professor de Física, 1(1), p. 1-14. Disponível em: http:/ / periodicos.unb.br/ojs311/index.php/rpf/article/ (Acessado: 5agosto2018).

NOVAK, J.D. and GOWIN, D. B. Learning How To Learn. New York: Cambridge University Press. 1984.

LEITÃO, L. I.; TEIXEIRA, P F DornDeles; DA ROCHA, F S. A vídeo-análise como recurso voltado ao ensino de física experimental: um exemplo de aplicação na mecânica. Revista Electrónica de Investigación en Educación en Ciencias, v. 6, n. 1, p. 18-32, 2011. 
PACHECO, S. M. V.; DAMASIO F. (junho de 2009), Mapas conceituais e diagramas V: ferramentas para o ensino, a aprendizagem e a avaliação no ensino técnico, disponível em http:/ /www.cienciasecognicao.o1

PACHECO, S. M. V.; DAMASIO, F. Mapas conceituais e Diagramas V: ferramentas para o ensino, a aprendizagem e a avaliação no ensino técnico, Ciências $\mathcal{E}$ Cognição, v. 14, n. 2, p. 166-193, 2009.

SILVA, F. R.; SOUZA, M. C. S. A formação inicial de professores de física para a abordagem de ensino CTS (Ciência, Tecnologia e Sociedade) e o uso do diagrama epistemológico de Gowin. Revista Educação, Cultura e Sociedade, v. 2, n. 1, 2012.

TAO, P.K., GUNSTONE, R.F. Conceptual Change in Science through Collaborative Learning at the computer. International Journal of Science Education. v. 21(1), pp.39-57, 1999.

TRABACH, A. R. S. A Atividades Experimentais em Sala de Aula de Física baseadas na Utilização da Vídeo-Análise e Estruturadas a partir do Diagrama V. 2018. Dissertação de Mestrado - Universidade Federal do Espírito Santo, Mestrado Nacional Profissional em Ensino de Física, Polo 12, Vitória, 2018.

WESOLY, C. E.; COSTA, S. S. C. O Vê de Gowin como mediador de significados para aulas de laboratório de Física no Ensino Médio. In: ENCONTRO NACIONAL DE APRENDIZAGEM SIGNIFICATIVA, 2., 2008, Canela. Anais. Rio Grande do Sul, 2008. 